\title{
ITD Data Quality Maturity (A Case Study)
}

\author{
Hewa Majeed Zangana \\ Department of Computer Science / College of Computer Science and IT / Nawroz University / Kurdistan Region of \\ Iraq
}

\begin{abstract}
Nowadays, more and more organizations are realizing of importance of their data, because it can be considered as an important asset in present nearly all business organizational processes. Information Technology Division (ITD) is a department in the International Islamic University Malaysia (IIUM) that consolidates efforts in providing IT services to the university.

The university data management started with decentralized units, where each center or division has its own hardware and database system. Later it improved to become became centralized, and ITD is now trying to one policy across the whole university. This will optimize the high performance of data management in the university. A visit has been done to ITD building and a presentation has been conducted discussing many issues concerning data management quality maturity in IT division at IIUM. We got some notices like server's room location, power supply and backup and existence of data redundant. These issues are discussed in details in the next sections of this paper and some recommendations are suggested to improve data quality in the university.

The quality of the data is very important in decision making, especially for a university that is trying to improve its strategy towards a research university and rise its rank among the World University Ranking.
\end{abstract}

Keywords: Authority, Data, Quality, Maturity, ITD.

\section{Introduction}

Quality plays an important role as one of the competitive powers for those companies which run businesses in the Information Society (Drucker. 1985). With this trend, data quality of the information system is regarded as more important because it is the basis of the information quality. Low quality data bring several negative effects to the business users such as dropping of customer satisfaction, high running cost, inefficient decision making process, and sluggishness of the corporate strategic performance (Rye et. tal. 2005).

Many efforts have been made in order to assure the quality of the running software, although not of the data. But this situation is changing due to new status of data: at last, organizations have realized data is one of the most important assets for them (Huang et tal. 1999).

\section{Background:}

ITD was established in 1998, it is a division within the International Islamic University Malaysia (IIUM) created to consolidate efforts in providing IT services to the campus community including branch campuses. In this respect, ITD provides to all Faculties, Divisions and Centers in IIUM. ITD plans and implements IT projects as well as support and maintains its operations on behalf of the users.

\subsection{Information Technology Division}

ITD plays as crucial role in ensuring that the University maintains its character as a premier university which ties together information and multimedia technologies in every aspect of its activities. 


\subsubsection{ITD Structure}

ITD is made up of the following 7 functional departments:

1. Administration and Finance Department (ARIFe).

2. ICT Governance Department (ITG).

3. Email System, Database, Security and R\&D (REDS) .

4. Project Based for Application Department (PEARL).

5. Operational Services for Application (OSA).

6. Network Telecommunication Department (NAT).

7. Computing and Server Management Department (CORE).

\subsubsection{Management Commitment}

The Management always gives its commitment to the development and implementation of the quality management system and continually improving its effectiveness by:-

- Communicating to the organization on the importance of meeting customer needs by following the stated rules and regulations.

- Establishing and reviewing the quality policy.

- Ensuring that the quality objectives are established and monitored.

- Conducting management reviews.

- Ensuring the availability of resources.

\subsubsection{Responsibility and Authority}

The Management of ITD has ensured that the responsibilities and authorities are defined and communicated within the organization.

Based on the organizational structure, ITD has the role of providing the services in "Management of ICT Services and Application System" to all students and staff of IIUM. ITD has set up function units to ensure the smooth running of the Division.

2.2 Data Quality Maturity

Quality of data can be define Data quality is defined as follows: data has quality if it satisfies the requirements of its intended use.

Quality plays an important role as one of the powerful competition advantages for those companies that run businesses in the information society.

For an easy way to determine organization's level of data quality maturity is to look at the current data quality improvement activities (fig. 1) (Adelman et.al., 2005)

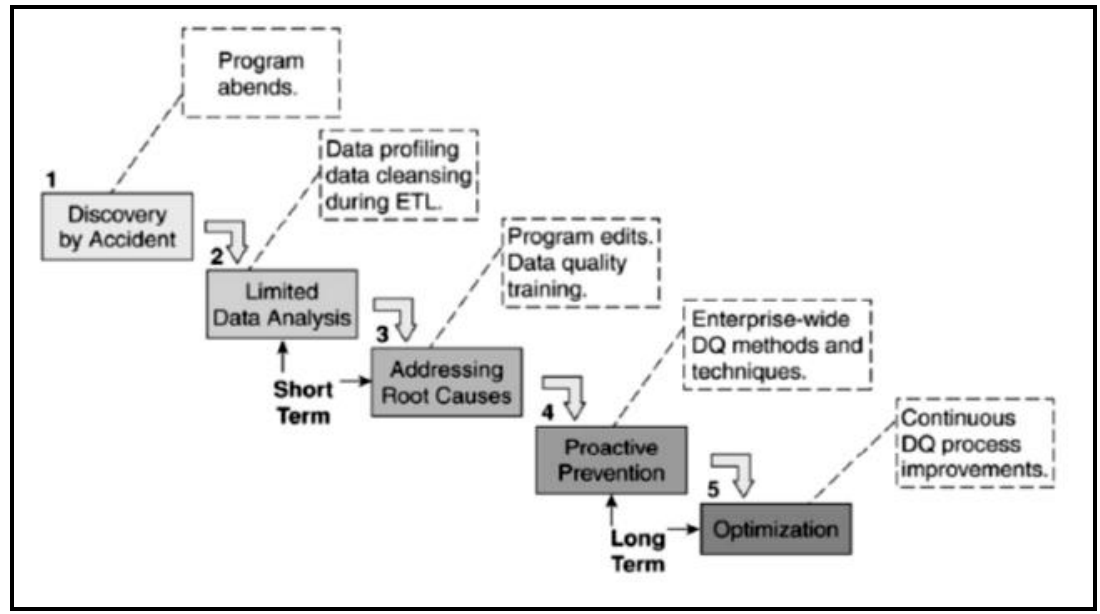

(Figure 1) Data Quality Maturity Levels

Quality level according to Adelman can be defined as the following five levels: Uncertainty, Awakening, Enlightenment, Wisdom and Certainty.

\section{Purposes}


The purpose of this paper is to show and assess the data quality maturity level of the International Islamic University.

\section{Data Collection}

Data Collection has been done by visiting ITD and meeting data base administrator and employees. A presentation conducted by them, showing the structure of the ITD and its departments' functions. We have asked some questions and discussed with them about the current state of the university database and its servers. We also got the chance to see the university data server at Gombak Compose.

\section{v. Findings - Data Quality Maturity}

In summarizing the data we've collect, we found the following points:

1) ITD division established in 1998 after 15 years of the university establishment after all other divisions and faculties has already started using their information systems. Some used market available applications to manipulate with their data, and some other developed a special one. So there was a heterogeneous state of databases systems.

Now, ITD has overcome this issue in almost all divisions in the main compose of IIUM at Gombak. The university has its software and hardware policy and all the divisions follow the policy and try to manage their software and data according to this policy. However, the administrator admitted that there is still certain level of data redundancy. There still divisions that have its own database system and sever. As an example: IIUM Library, which depends completely on IT. This also could cause redundant of data and IT staff, like it has its own copy of students' information and may make inconsistency in their data when an update occurs.

2) The power supply and backup systems for the servers is complex due to the many data servers and its various services. The used cooling system is sophisticated to keep servers' temperature suitable. These systems need huge amount of efforts to manage. If a power shortage occurs in ITD division, it will affect ITD services and shut it down entirely. The current backup system in ITD division is capable to provide one hour supply only. This will make university data to be unavailable for a period of time if it takes more time to be handled.

3) Some of the database systems are usually under pressure in the peak time, as an example at the beginning or the end of a semester, student record database servers may go down or face a severe delay due to huge number of requests from the students when checking their results.

4) There is also a state of inconsistency in the system. Sometimes one student is recorded with two metric numbers (ID No.) like when a student graduates from a faculty and continuo his study in master level. There is also a case when a student get admission in one faculty, then after one semester or more he get admission in another faculty and change his program. Is these cases, student data like matric number, name, and passport information will be saved in the database twice and will be duplicated.

5) The position of the database storage system is also important to be considered. IIUM data servers are located in the ground floor near the ITD office. This make it unsafe from natural disasters in case it occurs, like it could be exposed to floods, in particularly considering the raining weather in Malaysia. The data servers should be located in a more secure place to avoid such cases, and there must be backup systems that can provide continuous service if a damage occurs.

\section{Recommendations}

Our recommendations are:

1) There are many new tools that can be used to integrate data in the multi-servers state, like NaviCAT Premium an easy and simple tool, which have the ability to connect between various types of database system, (Qracle, MySQL, ...) through various ways (http, Local Network, ...). This can solve the problems of redundancy by linking all systems and improve the Data Management Quality in IIUM.

2) For data servers to be safer, they should be moved and placed from current room in the first floor to a higher place such as second or third floor of ITD building.

3) Although it is too complex and costly, a Data Warehouse is recommended to overcome and remove the redundant data of students especially students who continue study from undergraduate to postgraduate, 
old data that is no more used should be archived in case there is an investigation for strategic studies related to students information.

\section{Conclusion}

At the end of this paper, we found that ITD has not overcome all issues data quality in the university. Most because it established after all other divisions already started using IT services and designed and developed their own applications to manage data. There is also the multi -compose issue that the university has three composes, main in Gombak, Kuala Lumpur, one in Kuantan, and the other is in the south of Kuala Lumpur. Integrating their servers requires using online techniques, which arise security issues. Many points have been noticed and discussed by this report, and some recommendation has been done for the improvement of data management in IIUM.

\section{References}

[1] About ITD. IIUM Website (http://www.iiu.edu.my/itd/about/about.shtml).

[2] Adelman, S., Moss, L., and Abai, M. (2005) "Data Strategy," Addison-Wesley.

[3] Huang, K.T., Lee, Y., Wang, R. (1999) Quality Information and Knowledge. Prentice Hall, Upper Saddle River.

[4] Kyung-Seok Ryu, Joo-Seok Park, \& Jae-Hong Park. (2005). A Study on Data Quality Management Maturity Model. Electronics \& Telecommunications Research institute (ETRI).

[5] lsmael Caballero and Muiioz-Reja Mario Piattini Velthuis. (2003). Data Quality Management Improvement

[6] Peter F. Drucker. (1985). Playing in the Information-Based -Orchestra. The Wall Street Journal, June 4,1985.

[7] Hewa Majeed Zangana. (2017). Library Data Quality Maturity (IIUM as a Case Study). IOSR-JCE March 29, 2017. 